\section{Methacholine induced headache}

\author{
Carmen Carratala, Joaquim G Gea, \\ M Carmen Aguar, Santiago Grau, \\ Joan M Espadaler-Medina, \\ Joan $M$ Broquetas
}

\begin{abstract}
A lung function technician developed episodes of headache, probably related to the use of methacholine. The headache disappeared with breathing $100 \%$ oxygen. Cholinergic agents are known to induce headaches but the mechanism remains unclear. Vascular factors could be implicated. (Thorax 1995;50:319)
\end{abstract}

Keywords: methacholine, headache.

Headache is a common symptom that occasionally gives rise to disability. Cluster headache attacks are a specific clinical form of headache. ${ }^{1}$ Although its pathogenesis still remains controversial, different toxic and metabolic agents such as monosodium glutamate, nitrates, and histamine can induce it. $^{2}$

We report the case history of a technician working in a lung function laboratory who presented with repeated episodes of headache mimicking cluster headaches and related to the use of methacholine in bronchoprovocation trials.

\section{Case report}

A 41 year old woman, non-smoker with no previous illness, had been working in the lung function laboratory for the previous 10 years. She had occasionally suffered from severe hemicranial headaches with temporofrontal predominance which normally lasted 2-3 hours. Ocular oedema, ptosis, photophobia, phonophobia, and flushing were also present. The headache did not improve with treatment which included paracetamol, non-steroidal anti-inflammatory drugs, and codeine. Above all, the symptoms appeared to be related to the use of methacholine used in bronchoprovocation tests. The technician obtained the prepared solutions from the pharmacy and these were nebulised by the patient. Although she did not initially use gloves, this precaution was later taken to prevent the possibility of a skinmediated mechanism. The whole procedure was performed indoors, in a room equipped with a mechanism for continuous air renewal. The physical examination when a headache was present was normal, except for the abovementioned symptoms and signs. As a clusterlike headache was suspected, treatment with
$100 \%$ oxygen was administered for 15 minutes during one of the episodes. The technician breathed through a mouthpiece and a two-way valve with the inspiratory arm connected to a 50 litre Douglas bag (WE Collins, Braintree, Massachusetts, USA) containing $100 \%$ oxygen. The bag was washed out twice before the technician began to breath from it. The headache progressively disappeared and had cleared when oxygen breathing was stopped.

\section{Discussion}

Methacholine is the $\beta$-methyl homologue of acetylcholine, the main neurotransmitter of the cholinergic system. Acetylcholine is a parasympathomimetic agent characterised by minor nicotinic action and a predominance of muscarinic effects. ${ }^{3}$ Side effects resulting from the activation of muscarinic receptors in different organs and tissues (heart, blood vessels, digestive and urinary tracts, respiratory system, eyes, central nervous system, and exocrine glands) can occur after drug administration. ${ }^{45}$ Methacholine (a substance with similar effects) is used in bronchoprovocation tests and is administered by inhalation. Fortunately, side effects are rare using this method. ${ }^{6}$

In our case report the close and repeated association between the onset of symptoms and the use of methacholine made an adverse drug reaction probable. The likelihood of a drug causing an adverse event is usually based on clinical judgement, but a more objective assessment is possible using Naranjo's weighted score which is one of the most valid and widely used methods for this purpose. ${ }^{7}$ This method assigns a score (0-13 points) for 10 different items and classifies the probability of an adverse drug reaction into "definite" ( $\geqslant 9$ points), "probable" (5-8), "possible" (1-4), and "doubtful" $(\leqslant 0)$. Using this system the Naranjo score was between 8 and 11 , making the cluster-like headache a "definite to highly probable" adverse drug reaction.

The pathogenesis of these headaches is not known. Cholinergics can induce headache ${ }^{6}$ but the mechanism remains unclear. The headache attacks in the present report were very similar to those in a cluster of histaminic headache, ${ }^{1}$ however, suggesting a vascular mechanism.

The authors acknowledge Joseph A Salazar for his help with editing.

1 Horton BT. Histaminic cephalgia. Lancet 1952;72:92-108.

2 Headache and other craniofacial pains. In: Adams R, Victor $R$, eds New York: McGraw-Hill, Principles of neurlogy. 1985:129-48.

3 Taylor P, Brown JH. Acetylcholine. In: Siegel G, Agranoff B, Albers RW, Molinoff P, eds Basic neurochemistry. New York: Raven Press, 1989:203-31.

4 Dutz W. Drugs affecting autonomic functions or the extrapyramidal system. In: Dukes MNG ed Meyler's side effects trapyramidal system. In: Dukes MNG ed Meyler's side
of drugs. 12th edn. New York: Elsevier, 1992:325.

5 The turnover of acetylcholine. In: Pycock CJ, Taberner PV, eds. Central neurotransmitter turnover. London: Croom
end Helm, 1981.

6 Sewester CS. Methacholine. In: Sewester CS, ed. Drug facts and comparisons. St Louis: JB Lippincott, 1990: 2407-8.

7 Naranjo CA, Busto U, Sellers EM, Sandor P, Ruiz I, Robert EA, et al. A method for estimating the probability of adverse drug reactions. Clin Pharmacol Ther 1981;30:239-45. 